\title{
Investigating the business value of information management
}

\author{
R. Saloojee \\ Department of Business Management \\ University of Johannesburg \\ Auckland Park \\ ridhwaan.saloojee@sappi.com \\ D. Groenewald \\ Department of Business Management \\ University of Johannesburg \\ Auckland Park \\ dgroenewald@uj.ac.za
}

\author{
A.S.A. du Toit \\ Centre for Information and Knowledge Management \\ University of Johannesburg \\ Auckland Park \\ adutoit@uj.ac.za
}

Research on the effect of information management on organizational performance is an important issue. The primary problem of the business value of information is embedded in the following reasoning: information management creates business value indirectly but creates business costs directly, making the evaluation and measurement of information management and the benefits thereof difficult for organizations. In this study an empirical survey was conducted in ten large South African organizations to establish practices and norms in managing the business value of information management, information management investment and benefits evaluation. The most common criteria considered to be important were the ability to adapt and support business changes and the stability and quality of information management services to the user community.

Key words: Information management, business value, benefits methodology

Received 30 November 2006; accepted January 2007

\section{Contents}

1. Introduction

2. Defining the business value of information management 
3. Strategic alignment of information management

4. Approaches to measuring information management investments

4.1 Evaluation methods for tangible benefits

4.2 Evaluation methods for intangible benefits

4.3 Information management evaluation method for risks

5. Empirical survey

5.1 Research methodology

5.2 Findings

5.3 Summary of findings

6. Conclusion

7. References

\section{Introduction}

Over the last decade, the business value of information has received considerable interest from both academics and the business community. While some authors such as Segards and Grover (1994:2) attribute large productivity improvements, substantial value added contribution and impact on business performance, other authors such as Brynjolfsson (1993:67) report that information management has not had any bottom line impact.

Information managers have found it increasingly difficult to justify rising information management expenditures and are often under pressure to find ways of measuring the contribution of the organization's information management investments to business performance, as well as to find reliable ways of ensuring that the business benefits from information management investments are realized. This problem has become more complex as the nature of information management investments and the benefits that can be delivered have evolved over time and changed rapidly. Furthermore, the evaluation of information management investments is a complex mix of financial, organizational, social, procedural and technical elements, many of which are currently either avoided or dealt with ineffectively by organizations (Pervan 1998:95).

Information management has changed the way in which organizations are conducting business and the way in which organizations compete with each other (Abdul-Gader and Kozar 1995:536). Information management is also seen as a fundamental method of gaining strategic and competitive advantage (Remenyi, Money and Twite 1993:4-6; Segards and Grover 1994:1). Organizations are continuing to invest large amounts of money in information management, in anticipation of a material return on investment (ROI). There is, however, doubt as to whether information management investment has proven economically successful (Willcocks and Lester 1996:15). Lubbe (2002:2) notes that, as information management investment costs are high, it is essential that managers make certain that investments in information management are economically justifiable. This is especially true for developing countries such as South Africa, where reserves need to be carefully directed into areas of high return so as to ensure economic growth (Lubbe 2002:2). Information management investment evaluation has become an important issue and interest in the area has grown over the last ten years. Therefore, an increasing number of organizations will attempt to establish, formulate and implement information management investments that will meet the organization's needs for efficiency and effectiveness (Earl 1992:35).

For the purpose of this article, information management is defined as 'the planning, organisation, development and control of the information and data in an organisation and of the people, hardware, software and systems that produce the data and information' (Duffy and Assad 1989:520). 
It is difficult to identify information management investments that will support organizational strategies. To establish a method that specifies how organizations can realize information management benefits would be of significant practical value to information managers. Similarly, the selection of information management investments requires details and advice on how each investment can be helpful to information managers. Research on practical formulation and selection issues, as well as the eventual effect of information management on organizational performance, is an important issue that demands attention. The strategic planning of information systems seeks to align information management investments with business strategies to maximize the opportunity for overall competitive advantage through information management. The life-cycle emphasis that Ward, Taylor and Bond (1996:214-225) place on evaluation not only considers the pre-investment appraisal and post-implementation evaluation processes, but also how organizations ensure that the benefits claimed are actively managed through to realization.

Another approach to the apparent inadequacy of investment appraisal techniques has been to develop appraisal methods such as information economics and return on management (Strassman 1990:494). Ward, Taylor and Bond (1996:224) conclude that traditional evaluation methods are considered to be unsatisfactory and are not applied widely or consistently. More sophisticated methods also do not appear to be the answer to evaluating information management investments.

According to Symons and Walsham (1988:119), the potential use of information management as a competitive weapon has become more evident in organizations. There is a lack of understanding of the impact of the proper information management investment evaluation and benefits realization process. Consequently, the capacity of many organizations to assimilate and apply information management lags behind the available opportunities. It is not difficult, therefore, to identify that the measurement of the business value of information management investment has been the subject of considerable debate by many academics and practitioners (Ballantine, Galliers and Stray 1996:129-141; Hitt and Brynjolfsson 1996:121-142). The difficulties in measuring benefits and costs are often the cause for the uncertainty about the expected benefits of information management investment and hence are the major constraint to information management investments (Renkema and Berghout 1997:2).

Evaluation is often ignored or carried out inefficiently or ineffectively because of the elusive and complex nature of information management (Serafeimidis and Smithson 1996:206). Therefore, the question remains, how can the business value of information management be realized?

According to Van der Zee (1997:2), many attempts have been made to measure the value of information management according to a variety of criteria. Despite the fact that a number of studies have found contradictory evidence on whether the benefits have materialized from information management, organizations continue to invest large amounts of money in IT equipment and related technologies (Willcocks 1994:3). In recent years, many senior managers have come to realize that it is increasingly difficult to justify the costs surrounding the purchase, the development and the use of IT (Fitzgerald 1998:16). According to Hochstrasser and Griffiths (1991:19), few organizations consistently state that information management is certainly value for money. Evaluating information management investments is problematic due to the fact that the benefits of information management are intangible and as a result, calculating the return on investment (ROI) is often difficult. In addition the valuecreating process in information management is unclear, traditional metrics do not capture the business value of information management and many information management projects do not obtain the intended objectives. 
The primary problem of the business value of information management is embedded in the following reasoning: information management creates business value indirectly but creates business costs directly, making the evaluation and measurement of information management and the benefits thereof difficult for most organizations. To solve the problem, the following questions were addressed in this research:

- What does the business value of information management mean?

- How does information management influence and support an organization's strategy?

- What are the common approaches to evaluating and measuring information management investments?

- How do organizations manage and realize the benefits of information management?

top

\section{Defining the business value of information management}

The Butler Cox Foundation (1990:3) states that obtaining value from information management is one of the main concerns of business managers and there is no single measure that can be used to conclusively prove the business value of information. Glazer (1993:110) notes that organizations that successfully integrate an information management strategy with the organization's business strategies do so by focusing on the information as the carrier of value and source of competitive advantage, rather than on technology. In a study on the business value of information management, Mukhopadhyay (1995:138) states that controversy exists regarding the impact of information on organizational performance and that investments in IT places increasing pressure on managers to justify the outlay of the investment by quantifying the business value of information management.

According to Fulton (2004:2), the key to information management investment success is to measure results in business terms by applying a business language and common business metrics for demand management, supply management and supporting services. There are three essential elements that comprise a significant information management initiative (Fulton 2004:2):

- Business objectives - goals, strategies or tactics that the information management initiative addresses

- Implementation - technical and business design, deployment and operation

- Business outcome - assessing the success of how the initiative meets its objectives.

Fulton (2004:3) concludes that the business outcome, which is created to justify an information management initiative, is the business value of information management.

\section{Strategic alignment of information management}

Alignment enables an organization to maximize the organization's information management investments and achieve alignment with the organization's business strategies and plans, leading to greater profitability (Papp 1999:367). The alignment of information management and business strategy to incorporate the capabilities of IT and to transform the business has increased in importance as organizations strive for competitive advantage in a diverse and changing marketplace (Faltermayer 1994:52). Therefore, there has been a significant amount of research and insight into the links between business and information management (Chan and Huff 1993:8-10; Luftman, Lewis and Oldach 1993:198-221) and the role of partnerships between information management and business management (Keen 1993:17-39), as well as 
the need to understand the transformation of business strategies resulting from the competitive use of information management (Davidson 1993:65-79). Organizations have been able to change not only the business scope, but the organization's infrastructures as well, as a result of innovations in information management (Keen 1991:24).

Traditional methods of developing business strategies have failed to take full advantage of information technology (IT) (Papp 1999:367). Technology was treated as a cost centre or viewed as an expense rather than an enabler of business value. Strategic alignment highlights the role of information management in the development of business strategies, the strategic fit between strategy and infrastructure as well as a functional integration between business and information management (Papp 1999:370).

Information management has become an important enabler of business strategies in areas of mass customization, competitive differentiation, quality improvements and process automation and improvement (Bruce 1998:16). According to Earl and Feeny (1994:12), IT organizations have added value to an organization's effectiveness by acting as change agents, focusing on business imperatives, and helping to achieve effectiveness and efficiency. Barney (1991:101) states that research on IT/business strategy alignment has shown positive linkages among competitive strategy, information management and performance. The alignment of business and information management strategies has been used by organizations to create and improve efficiencies, reduce costs, create barriers to entry, improve customer, buyer and supplier relationships and to create new products and business solutions (Adcock, Helms and Wen-Jang 1993:10). Davenport (1995:5) has called information management one of the prime enablers of change that has created 'a new way of working'.

According to Bruce (1998:16), the consequences of organizations that fail to strategically align information management and business strategies are that they face increasing financial and opportunity costs. Szgenda (1999:9) states that organizations that have successfully aligned information management and business strategies on average pay less on IT per user than those who fail to align. Bruce (1998:16) believes that the failure to align business strategy with information management will result in the following issues:

- The organization will not be able to invest IT money wisely and create mechanisms for investment and funding.

- The organization will not be able to gain credibility with the business and provide proactive rather than reactive services.

- The organization will not be able to attract, retain and resource the appropriate skills.

- The organization will not be able to measure information management's contribution to the business.

- The organization will not be able to communicate strategy to employees and link strategy to budgets (Norton 2002:1).

Weill and Baroudi (1990:8) recognize and agree that information management success is a difficult concept to define. Delone and McLean (1992:60-95), through a comprehensive literature review of information management success measures, conclude that in searching for an information management success measure, rather than finding none, there are nearly as many measures as there are studies. Henderson and Venkatraman (1993:6) argue that the 'inability to realise value from IT investments is, in part, due to a lack of alignment between the business and IT strategies of organisations'.

Several frameworks have been proposed to assess the strategic issues regarding the role of information management as a competitive weapon (Papp 1999:367). These frameworks serve to define the two dimensions that comprise the alignment model and include (Henderson and 
- Fit. Defined as the alignment of external and internal environments within an organization

- Linkage. The alignment of the information management and business domains of an organization.

Henderson and Venkatraman (1993:4-16) have developed a conceptual model, the strategic alignment model (SAM), to address the issue of exploiting information management capabilities in a competitive role and for the strategic management of information.

\section{Approaches to measuring information management investments}

Literature offers several representative information management investment evaluation methods of interest both to practitioners and researchers (Molina 2003:15). Most information management evaluation methods for tangible benefits are designed to compare costs of investment alternatives or attempt to provide procedures for the quantification of benefits and risks (Lubbe 2002:22). Such methods tend to rely on the help of technical personnel to provide management with accounting data for evaluation. Methods for intangible benefits put emphasis on the process of obtaining agreement on objectives through a process of exploration and mutual learning. Such methods tend to rely on a thorough understanding of the opportunities and the threats of failure of the information management investment (Lubbe 2002:22).

\subsection{Evaluation methods for tangible benefits}

The major categories for tangible benefits include ROI, cost-benefit analysis (CBA), return on management (ROM) and information economics.

\subsubsection{Return on investment (ROI)}

ROI methods have been widely discussed as possible evaluation procedures for information management investment (Farbey, Land and Targett 1993:41). There are three commonly used ROI methods, namely net present value (NPV), discounted cash flow (DCF) and payback period. Methods based on ROI are generally regarded as more theoretically correct and practically feasible approaches to capital investment appraisal (Farbey, Land and Targett 1993:41). Such methods are also commonly accepted in many organizations as the standard ways for selecting capital investment projects. ROI methods, however, are unable to capture many of the intangible benefits that information management brings to the organization (Molina 2003:31).

\subsubsection{Cost-benefit analysis (CBA)}

CBA tries to overcome the problem of ROI by finding some surrogate measure for intangible costs or benefits that can be expressed in monetary terms. The approach attempts to deal with two problems, namely the difficulty of quantifying the value of benefits that do not directly accrue to the investor in the project and the difficulty of identifying the benefits or costs that do not have an obvious market value or price (i.e. intangible factors). The CBA method is useful where the costs and benefits are intangible, but the method requires the existence of a broad agreement on the measures used to attach a value to the intangibles (King and Schrems 1978:20).

\subsubsection{Return on management (ROM)}

Strassmann (1997:37) argues that information management serves primarily to help the 
management perform a management's role and hence has introduced the concept of a valueadded productivity measurement system as an approach to identify the impact of information management on business unit performance. In this approach, all measures of productivity use the simple ratio of 'output/input'. The main problem is how to define the output of management. Strassmann (1997:37) defines the output of management as management's value-add, which is simply everything remaining after subtracting all the direct operating costs from the value-added due to direct labour.

\subsubsection{Information economics}

Information economics is a variant of cost-benefit analysis, tailored to cope with the particular intangibles and uncertainties found in information systems projects (Parker, Benson and Trainor 1988). The decision-making process used in information economics methodologies is based on a ranking and scoring technique of intangibles and risk factors associated with the information management investment. It identifies information management performance measures and uses them to rank the economic impact of all the changes on the organization's performance caused by the introduction of IT especially (Molina 2003:32). The limitation of information economics is that it does not deal with the mechanism but only with the outcomes (Ahituv 1989:315-325). Another limitation is the focus on simple, idealized settings that can be modelled with applicable mathematical models, often requiring many simplifying assumptions (Bakos 1995:129).

\subsection{Evaluation methods for intangible benefits}

\subsubsection{Multi-objective, multi-criteria (MOMC)}

This method attempts to develop a general measure of utility where utility is defined as the satisfaction of an individual's preferences. The method is based on the belief that people's behaviour is determined to some extent by the feeling that preferences are recognized (VaidRaizada 1983:44).

\subsubsection{Value analysis (VA)}

This method emphasizes value rather than cost (Rivard and Kaiser 1989:53). The method is based on the following three assumptions:

- Innovation is value driven and not cost driven.

- Intangibles can be identified and subjectively assessed but rarely measured accurately as surrogate measures are often used to satisfy the requirement for most inputs.

- An inevitable clash exists between the persons driven by cost and persons driven by effectiveness. This method was developed and used by several researchers such as Keen (1981:1-15) and Rivard and Kaiser (1989:53-56).

\subsubsection{Critical success factors (CSF)}

This method is used to explore the potential value of information systems. The approach is based on early works by McFarlan (1981:142-150) who proposes the concept of the success factors and invites the analyst to explore with executives the factors that are critical to the success of the business, in particular the factors that are important for the functions or activities for which the executives are responsible. Issues can be ranked by the executives into levels of importance.

\subsection{Information management evaluation method for risks}

\subsubsection{Real option (RO)}

According to Molina (2003:33), this method uses three basic types of data:

- Current and possible future business strategies 
- The desired system capabilities sought by the company

- The relative risks and costs of other IT choices that could be used.

The method can help assess the risks associated with IT investment decisions, taking into account that business strategies and system requirements may change.

\subsubsection{Portfolio approach (PA)}

The portfolio approach focuses on three important dimensions that influence the risk inherent in an information management investment (McFarlan 1981:148). These include:

- Size of the projects and workload to be handled by the system

- Experience of management with the technology

- Capability in handling complex, highly structured projects.

The portfolio approach, according to Molina (2003:34), suggests that an organization not only assesses relative risk for a single information management project, but also develops an aggregate risk profile of the information management investment.

\section{Empirical survey}

\subsection{Research methodology}

An empirical survey was undertaken in 10 large South African organizations to assess the understanding and activities performed by these organizations regarding the business value of information management. The total research group consisted of chief information officers, information managers and IT directors across each of the selected organizations. The selected organizations had to meet the following criteria:

- The revenues over the last financial year must have exceeded R100 million

- The total employee headcount must exceed 10000 employees

- The organization must be listed on the Johannesburg Stock Exchange.

The respondents were identified by the researchers with the assistance of the human resource departments in each of the selected organizations. The respondents had to meet the following criteria to be included in the sample:

- The respondent must have a senior position in each of the selected organizations either on a global or regional level

- The respondent must be involved in the information management decision-making process for the organization.

A questionnaire was used to collect data regarding the perceptions of the business value of information, information management investment and benefits management. The questionnaire consisted of both open-ended and closed-ended questions. The questionnaire was based on the existing questionnaire originally developed and conducted by Ward, Taylor and Bond (1996) and then re-used by Lin and Pervan (2001). The questionnaire consisted of the following sections:

- Section A: Personal information

- Section B: Business value of information management

- Section C: Information management investment

- Section D: Benefits management

- Section E: The future. 
A total of six usable sets of questionnaires were received and used for the purpose of the research. All respondents were from an IT background and all respondents held senior information management positions, which included three chief information officers and three IT directors who indicated that there was one reporting level between the IT director and their respective chief information officers.

\subsection{Findings}

\subsubsection{Business value of information management}

The first section (questions one to three) focused on the business value of information management and asked the respondents what the business value of information management meant to the respondents. The responses were similar and all respondents shared a common view that the business value of information management is the successful enablement of business objectives and strategies that result in business improvement. Other responses included that the business value of information management is to support the core business and that information management must be implemented holistically and applied to address the strategic direction of the business. The responses comprised of some of the key elements found in Fulton's (2004) definition of the business value of information management in that information management is an enabler of an organization's strategies and objectives and allows the organization to improve business performance and competitiveness.

The respondents were asked which perspectives and/or criteria of the business value of information management were important to consider. The most common criteria that were important to consider was the ability to adapt and support business changes and the stability and quality of information services to the user community. Other criteria included process optimization, retention of organizational memory, improved communication and collaboration.

To conclude this section, the respondents were asked to indicate perceptions of the role of information management applications in the organization. Of the respondents, $66,7 \%$ disagreed that information management provided only a support role that was not critical to everyday operations. All respondents indicated that information management provided key operational processes that were essential for everyday operations and IT was used to develop processes that might become important in the future. Only $50 \%$ of the respondents believed that information management was of strategic importance to the organization. On the whole, the respondents viewed information management as having a key operational, strategic and high potential (future) role in organizations.

\subsubsection{Information management investment}

Questions four to nine focused on information management investment and evaluation. Respondents were asked what the respondent understood by the term information management investment. The common response (83,3\% of respondents) to this question was the investment in hardware and software, as well as implementation and change management. Other responses included the percentage of budget allocated to information management across operations, new development and R\&D projects.

Questions five and six asked if there was a process to monitor and realize those benefits that an information management investment should give. Of the respondents, 66,7\% answered 'Yes' and outlined the respective processes to monitor and realize those benefits that an information management investment should give, which included:

- Projects are audited after implementation

- Predicted ROI is measured against actual ROI. 
Benefits were identified during the initiation phase of a project and documented. Only quantifiable benefits were then tracked during the prototype, pilot and implementation phases of the system. Non-quantifiable benefits were documented for reference, for example user experience on new systems.

Of the respondents, 66,7\% indicated that someone in the organization was responsible for monitoring and realizing the benefits identified in a project. When asked if there was any evaluation and/or follow-up of those benefits that an information management investment should give and, if there was, which purpose did this follow-up have, 66,7\% said 'Yes' for different purposes including:

- Mainly driven from chief operating officer level and from a business case level for new projects

- To see if objectives were met by the project.

The benefits were recorded on a monthly basis and discussed during the projects and systems review sessions. When projects did not realize the benefits, they were re-evaluated and rescoped or closed, depending on the relevant action required.

This section concluded by asking respondents which methods were used for the evaluation of those benefits that an information management investment should give. All respondents used a common method of actual versus budget projections. Other methods also used were process monitoring and benchmarking. Actual versus budget or planned projections were consistent with the results found by Lin and Pervan (2001).

\subsubsection{Benefits management}

Questions 10 to 15 concentrated on benefits management. The respondents were asked to provide views of the benefits that senior managers perceived to be provided by information management. The most frequently cited benefits were cost reduction, process efficiency and satisfying information needs. Management control contained in systems and the enablement of staff to generate growth were perceived to be further benefits. These results are largely consistent with the findings of Ward, Taylor and Bond (1996) who list cost reduction, process efficiency and business necessity as some of the major perceived information management benefits.

Of respondents, 50\% indicated a very high level of confidence that information management was actually delivering benefits in their organizations. The average confidence level was 4,17 (out of a five-point scale ranging from 'not at all' to 'very'). The most quoted reason for this confidence was the fact that the organizations did track the value added via the benefits on the bottom line and therefore it was possible to evaluate the delivery of information management.

Respondents were asked about the adoption, usage and success with formal methodologies or process for various IT activities and revealed a very high adoption of methodologies for system development (100\%) and project management (100\%). Fifty per cent responded that they had an information management investment appraisal process and only 33,3\% indicated that their organization had a benefits management methodology in place. The findings are not consistent with both the finding of Ward, Taylor and Bond (1996) and Lin and Pervan (2001), where the adoption rates are slightly less for all methodologies.

Respondents indicated that systems development and project management were widely used (selected four out of a five-point scale ranging from 'not at all' to 'extensively') in 50\% and $66,7 \%$ of cases respectively. Of the respondents, $83,3 \%$ and $50 \%$ indicated respectively that a formal information management investment appraisal process and an information 
management benefits management methodology were either extensively used or not used at all. In terms of the effectiveness of those methodologies in ensuring successful information systems, respondents indicated that all methodologies were effective (selected four or five out of a five-point scale ranging from 'not at all' to 'extensively'). Overall, both systems development and project management methodologies were widely used and effective in ensuring successful information systems. However, both the information management investment appraisal process and benefits management methodology were rated as effective, ensuring successful information systems, but they were not widely used. An examination of those respondents who did have an information management investment appraisal process and benefits management methodology indicated the higher usage and effectiveness of these methodologies.

\subsubsection{Identifying and structuring benefits}

Questions 16 to 26 focused on identifying and structuring benefits. Respondent were asked what the underlying issues were that drove the organization's investment in information management. The most common responses were escalating IT costs and competitive changes in business environment, including compliance and governance, risk and business improvement requirements.

On being asked if the respondents have a process that ensures that information management projects are linked to business objectives, all respondents answered 'Yes' and outlined the processes used in the organizations, which included the overall information management strategy and that the information management investment was part and parcel of the business case for any new project. The most common benefits that respondents considered when planning information management projects were:

- Cost reduction

- Revenue increase

- Efficiency increase

- IT risk reduction

- Business risk reduction

- Improved service delivery

- Total cost of ownership.

The results above are consistent with the findings by Ward, Taylor and Bond (1996) in that the most common benefits identified were cost reduction, improved efficiencies and revenue generation.

Of the respondents, 66,7\% indicated that they had included intangible benefits in the information management investment appraisal process. However, only 50\% often regarded intangible benefits as major success criteria.

In terms of appropriateness, $50 \%$ of the respondents rated the methods and techniques employed by the organizations for deciding upon information management investments as less than 'very appropriate'. The average appropriateness level was 3,5 (out of a five-point scale ranging from 'not at all' to 'very').

Many of the respondents stated that information management and business management was 'often or always' responsible for preparing and submitting the justification for approval.

Of the respondents, $66,7 \%$ believed that the current process in the respondent's organizations identified all available benefits for a project. However, only 33,3\% believed that the current process adequately quantified the relevant benefits and the same number of respondents believed that the process overstated the benefits in order to get approval. These results are 
consistent with those of Ward, Taylor and Bond (1996).

Respondents were asked whether the organizations used pilot studies when implementing IT. 'Yes' was indicated by 66,7\%, with 50\% and 25\% respectively indicating that the objectives were 'often or always' to evaluate technology. Seventy-five per cent often used pilot studies to understand the benefits available while $50 \%$ 'sometime or often' used pilot studies to demonstrate how to realize the benefits. Overall the use of pilot studies to evaluate the benefits of IT investment was consistent with the findings by Lin and Pervan (2001:399).

\subsubsection{Planning benefits realization}

Questions 27 to 31 focused on planning benefits realization. All respondents indicated that the organization appointed a business project manager. The responses indicated that the primary roles of the business project manager were to:

- Ensure alignment between business and information management

- Project management and control, stakeholder management and organizational change management.

The survey conducted by Ward, Taylor and Bond (1996) found that the project manager's role was to be the interface between the business and information management. When asked how the organization ensures that IT projects will deliver benefits to all relevant users, the respondents mentioned user involvement and syndication as the only method. Other responses included that ensuring the IT projects will deliver benefits to all relevant users was not always feasible and that the pareto principle should be applied.

Of the respondents, 50\% mentioned that the organization did prepare a benefits delivery plan. These plans were 'sometimes' (33,3\%), 'often' (33,3\%) or 'always' $(33,3 \%)$ planned before the approval stage, 'sometime' $(67,7 \%)$ or 'often' $(33,3 \%)$ planned during the system design phase, 'rarely' (100\%) during implementation and 'never' (33,3\%) or 'rarely' $(67,7 \%)$ when the system had been implemented.

\subsubsection{Delivering the benefits}

Questions 32 to 34 focused on the delivery of benefits. Of the respondents $50 \%$ held formal reviews of activities associated with delivering benefits during the implementation process. Furthermore, as a result of monitoring benefit realizing activities, 66,7\% of the respondents made changes to either the system design or the implementation approach.

Respondents were asked who was responsible for ensuring that the benefits that had been identified were delivered. Of the respondents, 50\% 'always' believed that it was the senior management or the users who were responsible ensuring that the benefits which had been identified were delivered, $50 \%$ of the respondents 'often' believed that line/departmental users and IT specialists were responsible.

\subsubsection{Evaluating and reviewing results}

Questions 35 to 42 focused on the evaluation and reviewing of results. Respondents were asked on how organizations concluded whether or not an information management project had been successful. The common responses included 'within cost', 'on time' and 'meet user requirements'. These responses are consistent with traditional project success criteria of 'working, on time, to budget'. Of the respondents, 50\% believed that the projects needed to deliver only at least $80 \%$ of the benefits as stated in the business case for the project to be deemed a success.

Of the respondents, $50 \%$ indicated that the measure of success was 'sometimes' or 'often' defined before project approval, and 50\% stated that measures of success were 'rarely' 
defined after implementation. In addition, 50\% of the respondents mentioned that the measures of success were 'always' defined before implementation. This result is significantly higher when compared to Ward, Taylor and Bond (1996).

All respondents indicated that the organizations conducted formal post-implementation project reviews and that $50 \%$ of respondents 'often' or 'always' believed that the objectives of these reviews were for technical conformance, project management effectiveness and benefit delivery. The results are inconsistent with findings by Ward, Taylor and Bond (1996) and Lin and Pervan (2001:150).

The majority of respondents $(83,3 \%)$ stated that the organizations conducted some form of benefit evaluation and that the results were fed back to whoever approved the project. In addition, $67,7 \%$ of the respondents' organizations had a formal process to ensure that the lessons learned from implementations were transferred to future projects. The results are significantly high when compared to research by Lin and Pervan (2001:150).

\subsubsection{Potential for further benefits}

Questions 43 to 47 focused on the potential for further benefits. The majority of the respondents $(83,3 \%)$ did not believe that it was possible to anticipate all potential benefits at the project approval stage. However, $50 \%$ of the respondents claimed to have a process for identifying further benefits after implementation while $66,7 \%$ did not take any action after implementation to realize these further benefits.

Most respondents believed that there was significant scope for improvement in the current approach to managing information management benefits. The average significant scope of improvement (on a 1 to 5 scale) was 3,5. There appeared to be a potential paradox between the current confidence (average $=4,1$ ) that information management was delivering benefits to the organization and the view that there was significant scope for improvement (average = 3,5 ) in the way that benefits were being realized.

\subsubsection{Future}

Questions 48 to 50 focused on the future. Of the respondents, 66,7\% indicated that the respondents would like to change the information management investment evaluation and benefit realization process. The most common changes included a more formalized and accepted methodology. A third (33,3\%) of the respondents wanted more focus and discipline on project justification and support from business for the business case and realization. Other responses included more respect for intangible benefits and the willingness to re-scope or revisit a project when it had proved to be unsuccessful in the earlier stages.

\subsection{Summary of findings}

The aim of the survey was to establish the current South African organizations' practises and norms in managing the business value of information management, information management investment and benefits evaluation. In summary, the research findings are consistent with the research findings of Ward, Taylor and Bond (1996) and Lin and Pervan (2001). The overall understanding of the business value of information management by respondents is closely aligned to the literature in this study. The most common criteria of the business value of information management that were important to consider were the ability to adapt and support business changes and the stability and quality of information management services to the user community. Respondents viewed the business value of information management as having a key operational, strategic and high potential (future) role in organizations.

There was a strong emphasis on cost reduction and other benefits, and a high level of confidence in the delivery of those benefits. Most organizations used a formal methodology 
or process for information management investment evaluation. Many respondents considered the traditional finance-based evaluation techniques imperfect, and tried to incorporate intangible benefits into the process. The majority of respondents made use of pilot studies as part of the investment appraisal process. Perceived benefits from information management investments included cost reductions, process efficiency and satisfying information needs. Most organizations linked these benefits to business objectives and had a relatively high confidence in delivering the benefits, even though some respondents felt the benefits were often overstated at project approval stage. Further, most included intangible benefits in the project appraisal process but often failed to review the intangible benefits at a later stage.

Most respondents seemed to have an existing process for information management evaluation and benefits management, only one-third of the respondents claimed to have a formal benefits realization methodology. All respondents appointed a specific business project manager to manage the process and half of the respondents had a benefits delivery plan. Most had formal reviews during implementation and revised systems design as a result. All respondents performed post-implementation reviews and these reviews considered such aspects of the project as technical conformance, project management effectiveness and benefit delivery.

The overall adoption and use of formal methodologies, for example project management and system development methodologies, were high but lower for information management investment appraisal processes and even lower for the benefits management methodology. The effectiveness of all methodologies was rated high even though the use and adoption of the benefits management methodology were low.

About 66,7\% of the respondents believed that the current project justification process in the respondents' organizations identified all available benefits for a project. Only 33,3\% believed that the current process adequately quantified the relevant benefits and the same number of respondents believed that the process overstated the benefits to get approval. This seems to be inconsistent. Most respondents felt that there was significant scope for improvement in the current approach to managing information management benefits. There appeared to be a potential paradox between the current confidence that information management was delivering benefits to the organization and the view that there was significant scope for improvement in how benefits were being realized. Most of the respondents indicated that they would like to change the information management investment evaluation and benefit realization process to include a more formalized and accepted methodology.

Organizations that did use a benefits methodology:

- Had used an information management investment appraisal process

- Had a formal process to ensure that the lessons learnt from successful or unsuccessful implementation were transferred to future projects

- Had prepared a benefits delivery plan

- Believed that their current process adequately quantified the relevant benefits

- Had a formal process to identify any further benefits after implementation

- Held formal review of activities associated with delivering benefits during the implementation process

- Felt that there was scope for significant improvement in their current approach to managing information management benefits. 
The exploratory study in the form of a questionnaire revealed that South African organizations viewed the business value of information management as being the successful enablement of business objectives and strategies that result in business improvement. The benefits and the direct business value were measured by the use of traditional financial measures such ROI, NPV and CBA. In addition to the financial measures, some organizations had adopted an information management investment appraisal process and a benefits methodology that measured both tangible and intangible benefits. The study indicated that the organizations that utilized a benefits methodology had positive results in managing and realizing the business value of information management compared to the organizations that had not adopted a benefits methodology.

The correct understanding of 'the business value of information management' is imperative as this allows an organization to successfully decide how the organization will measure and realize the information management benefits from information management investments. This research defined the business value of information management as the measures that demonstrate how information management related changes and investments contribute over time to improved business performance, competitiveness and economic growth. This definition addresses the definitional problems in that the definition is generic and free of suggested or implied measures that result from a specific value perspective. The definition provides organizations with the ability to identify the appropriate information management evaluation measures in the context of information management investments.

The link that exists between information management and business is the organization's ability to harmonize the organization's overall strategy and information systems. Strategic alignment is the appropriate use of IT in the integration and development of business strategies and corporate goals. This linkage enables an organization to maximize the organization's information management investments and transform the organization to create and improve efficiencies, reduce costs, create barriers to entry, improve customer, buyer and supplier relationships and to create new products and business solutions. Strategic alignment highlights the role of information management in the development of business strategies, the strategic fit between strategy and infrastructure as well as a functional integration between business and information management. IT has become an important enabler of business strategies in such areas of mass customization, competitive differentiation, quality improvements and process automation and improvement. The exploratory study indicates that the business value of information management has a strategic and high potential role in organizations and has shown positive linkages among competitive strategy, IT and performance.

\section{References}

Abdul-Gader, A.H. and Kozar, K.A. 1995. The impact of computer alienation of information technology decisions: an exploratory cross-national analysis. MIS Quarterly 19(4):535-559.

Adcock, K., Helms, M. and Wen-Jang, K. 1993. Information technology: can it provide a sustainable competitive advantage? Information Strategy: the Executive's Journal 9 (Spring):10-15.

Ahituv, N. 1989. Assessing the problems of information: problems and approaches. Proceedings of the 10th International Conference on Information Systems, Boston, MA:315325.

Bakos, J. 1995. Are computers boosting productivity? Yes! Computerworld 3(2). [Online]. 
Available WWW: http://www.computerworld.com/news/1995/story/0,11280,15311,00.htm. [Accessed 15 December 2005].

Ballantine, J.A., Galliers, R.D. and Stray, S.J. 1996. Information systems/technology evaluation practices: evidence from UK organizations. Journal of Information Technology 11 (2):129-141.

Barney, J. 1991. Firm resources and sustained competitive advantage. Journal of Management 17(1):99-120.

Bruce, K. 1998. Can you alight IT with business strategy? Strategy \& Leadership 26(5):16.

Brynjolfsson, E. 1993. The productivity paradox of information technology.

Communications of the ACM 36(12):67-77.

Butler Cox Foundation. 1990. Getting value from information technology. Research report 75. London: Butler Cox.

Chan, Y. and Huff, S. 1993. Strategic information systems alignment. Business Quarterly 58 (1):8-10.

Davenport, T.H. 1995. Reengineering a business process. Harvard Business School Case Study. Boston, MA: Harvard Business School.

Davidson, W. 1993. Beyond re-engineering: the three phases of business transformation. IBM Systems Research 321):65-79.

DeLone, W. and McLean, E. 1992. Information systems success: the quest for the dependent variable. Information Systems Research 3(1):60-95.

Duffy, N.M. and Assad, M.G. 1989. Information management: strategy formulation and implementation. Cape Town: Oxford University Press.

Earl, M.J. 1992. Putting IT in its place: a polemic for the nineties. Journal of Information Technology 7(2):33-39.

Earl, M.J. and Feeny, D.F. 1994. Is your CIO adding value? Sloan Management Review 35 (3):11-20.

Faltermayer, E. 1994. Competitiveness: how US companies stack up now. Fortune 129 (8):52-64.

Farbey, B., Land, F. and Targett, D. 1993. IT investment: a study of methods and practice. Oxford: Butterworth Heinemann.

Fitzgerald, G. 1998. Evaluating information systems projects: a multidimensional approach. Journal of Information Technology 13(1):15-27.

Fulton, R. 2004. Defining the business value of IT. Gartner, Inc. Decision Framework, DF18-3219.

Glazer, R. 1993. Measuring the value of information: the information-intensive organization. IBM Systems Journal 32(1):99-110. 
Henderson, J. and Venkatraman, N. 1993. Strategic alignment: leveraging information technology for transforming organizations. IBM Systems Journal 32(1):4-16.

Hitt, L.M. and Brynjolfsson, E. 1996. Productivity, business profitability, and consumer surplus: three different measures of information technology value. MIS Quarterly 20(2):121142.

Hochstrasser, B. and Griffiths, C. 1991. Controlling IT investment: strategy and management. New Jersey, NY: Chapman \& Hall.

Keen, P. 1981. Value analysis: justifying decision support systems. MIS Quarterly 5(1):1-15.

Keen, P. 1991. Shaping the future: design through information technology. Boston, MA: Harvard Business School Press.

Keen, P. 1993. Information technology and the management difference: a fusion map. IBM Systems Journal 32(1):17-39.

King, J.L. and Schrems, E.L. 1978. Cost-benefit analysis in information systems development and operation. ACM Computing Survey 10(1):19-34.

Lin, C. and Pervan, G. 2001. A review of IS/IT investment evaluation and benefits management issues, problems and processes. In: Gembergen, S. (ed). Information technology evaluation methods \& management. Hersey: Idea Group Publishing.

Lubbe, S. 2002. IT investment in developing countries: an assessment and practical guide. Hersey: Idea Group Publishing.

Luftman, J., Lewis, P. and Oldach, S. 1993. Transforming the enterprise: the alignment of business and information technology strategies. IBM Systems Journal 32(1):198-221.

McFarlan, F.W. 1981. Portfolio approach to information systems. Harvard Business Review 59(5):142-150.

Molina, E.S. 2003. Evaluating IT investments: a business process simulation approach. Stockholm: Royal Institute of Technology.

Mukhopadhyay, T. 1995. Business value of information technology: a study of electronic data interchange. MIS Quarterly 19(2):137-156.

Norton, D.P. 2002. The alignment gap. CIO Insight. [Online]. Available WWW: http://www.cioinsight.com/article2,0,3959,283925,00.asp. [Accessed 21 December 2005].

Papp, R. 1999. Business-IT alignment: productivity paradox payoff? Industrial Management \& Data Systems 99(8):367-373.

Parker, M.M., Benson, R.J. and Trainor, H.E. 1988. Information economics. London: Prentice Hall.

Pervan, G. 1998. How chief executive officers in large organizations view the management of their information systems. Journal of Information Technology 13:95-109.

Remenyi, D., Money, A. and Twite, A. 1993. A guide to measuring and managing IT 
benefits. Oxford: Blackwell.

Renkema, T.J.W. and Berghout, E.W. 1997. Methodologies for information systems investment evaluation at the proposal stage: a comparative review. Information and Software Technology 39(1):1-13.

Segards, A.H. and Grover, V. 1994. Strategic group analysis: a methodological approach for exploring the industry level impact of information technology. Omega 22(1):1-6.

Serafeimidis, V. and Smithson, S. 1996. The management of change for information systems evaluation practice: experience from a case study. International Journal of Information Management 16(3):205-217.

Strassman, P.A. 1997. Computers have yet to make companies more productive. Computerworld 31(3):37.

Symons, V. and Walsham, G. 1988. The evaluation of information systems: a critique. Journal of Applied Systems Analysis 15:119-132.

Szgenda, R. 1999. Information's competitive edge. Information Week 720(1):4-10.

Vaid-Raizada, V.K. 1983. Incorporation of intangibles in computer selection decisions. Journal of Systems Management 33(11):30-36.

Van der Zee, J.T.M. 1997. In search of the value of information technology. Tilburg: Tilburg University Press.

Ward, J., Taylor, P. and Bond, P. 1996. Evaluation and realization of IS/IT benefits: an empirical study of current practices. European Journal of Information Systems, 4(2):214225.

Weill, P. and Baroudi, J. 1990. An empirical investigation of the relationship between firm performance and system success. Working paper no 15. Melbourne: University of Melbourne.

Willcocks, L. 1994. Information management: the evaluation of information systems investments. London: Chapman and Hall.

Willcocks, L. and Lester, S. 1996. The evaluation and management of information system investments: from feasibility to routine operations. London: Chapman and Hall.

\section{Disclaimer}

Articles published in SAJIM are the opinions of the authors and do not necessarily reflect the opinion of the Editor, Board, Publisher, Webmaster or the Rand Afrikaans University. The user hereby waives any claim he/she/they may have or acquire against the publisher, its suppliers, licensees and sub licensees and indemnifies all said persons from any claims, lawsuits, proceedings, costs, special, incidental, consequential or indirect damages, including damages for loss of profits, loss of business or downtime arising out of or relating to the user's use of the Website. 
ISSN 1560-683X

Published by InterWord Communications for Department of Information and Knowledge Management, University of Johannesburg 